\title{
Proportional Representation and Structure of Tunicae in Large Arteries in Rabbit
}

\author{
Dalma CSIBI ${ }^{1}$, Viorel MICLĂUŞ ${ }^{1}$, Cristian MARTONOŞ ${ }^{1}$, Cristian DEZDROBITU ${ }^{1}$, Vasile RUS ${ }^{1 *}$, Flavia \\ RUXANDA $^{1}$, Aurel DAMIAN ${ }^{1}$
}

${ }^{1}$ University of Agricultural Sciences and Veterinary Medicine, Cluj-Napoca, Romania

*Corresponding author e-mail: vasilerus2002@yahoo.com

Bulletin UASVM Veterinary Medicine 71(2) / 2014,

Print ISSN 1843-5270; Electronic ISSN 1843-5378

DOI:10.15835/buasvmcn-vm: 10548

\begin{abstract}
Large arteries from 2 rabbits were processed in order to make histological investigations, using two staining techniques: Goldner's Trichrome and Verhoeff. We noticed that the proportion of the three arterial tunicae modifies as they get farther away from the heart. The changes appear in tunica media, which gradually decreases, and tunica adventitia, which gradually increases. Structurally, we observed that the first arterial segments are typical elastic arteries (pulmonary trunk, ascending aorts, aortic arch and thoracic descending aorta), the next are transitional arteries (abdominal descending aorta, subclavian arteries, carotids), and the iliac arteries are typical muscular arteries.
\end{abstract}

Keywords: large arteries, rabbit, structure

\section{INTRODUCTION}

Blood is pumped by the heart and leaves with a large pressure, as intermittent jets. By their particular wall structure, large arteries transform the intermittent flow to a continuous one (Damian, 2001). Tunica media of large arteries participates in this process, especially through its elastic component and to some extent, through the muscular one. After the classical description, the media of large arteries is formed out of concentric elastic lamellae and there are some smooth muscle cells in between them (Leeson et al., 1985). The number of elastic lamellae differs from one author to another, which makes us believe that their number varies between certain limits even in the same species. As a matter of fact, some authors claim there is an increase in their number with age (Junqueira et al., 1998; Raica et al., 2004). Some authors sustain that the number of elastic lamellae is 40-60 (Lesson et al. 1985; Ross and Reith, 1985), while others say it is 30-50 (Raica et al., 2004), 5060 (Adlersberg et al., 1955), 40-70 (Junqueira et al.,1998), etc. The forementioned authors refer to the structure of large arteries in man. Raica et al. (2004) sustain that in humans, aorta and all its segments are typical elastic arteries and continue with transitional or mixed arteries (collaterals of abdominal aorta, external carotids, axillary and common iliac arteries). We found a small amount of information in the speciality literature on whether this situation is valid in all mammal species, as well as on the structure of each species.

\section{MATERIALS AND METHODS}

The biological material utilized in this investigation was represented by 2 clinically normal male rabbits (3 months old, common breed, $1,2 \mathrm{~kg}$ ) from a private breeder in Cluj county. After Ketamine and Xylazine cocktail anesthesia (Oana et al., 2006), the next arteries were brought out through anatomical dissection: pulmonary trunk, aortic arch, left and right subclavian arteries, left and right carotid arteries, thoracic descending aorta, abdominal descending aorta, left and right external iliac arteries. Samples from all these arteries were harvested and fixed in 10\% buffered formalin for three days. After dehydration in ethanol, the samples were clarified in n-Butanol 
and embedded in paraffin. $5 \mu \mathrm{m}$ thick sections were made and stained with Goldner's Trichrome (Mureşan et al., 1974) and Verhoeff methods. The microscopic samples were examined with a light microscope (Olympus BX 41, with an Olympus E 330digital photocamera) and images were captured. Using Adobe Photoshop (CS 2 V. 9.0.) program, we measured the thickness of every tunica and the obtained results were statistically analyzed with Microsoft Office Excel (2003) program.

\section{RESULTS AND DISCUSSIONS}

Arteries taken into study (graded as large arteries) present particularities depending on the anatomical area they serve. The proportion in which the three arterial tunicae are represented is not the same in all large arteries. Tunica media predominates and tunica adventitia represents approximately $15 \%$ in the first segments, but as it gets further away from the heart, the proportion between tunicae modifies.

The pulmonary trunk has a thin adventitia and a very thick media with a comparable structure in its all thickness. Muscle cells are not the majoritary component, but are present in approximately in the same density and distribution in all its thickness. Their disposition is not very regular: there are muscle cells with a circular, but also an oblique disposition. On Verhoeff's stain, we can observe that the media is prevalently elastic, with a certain polymorphism regarding the thickness and distance between the elastic lamellae. The orientation of the elastic lamellae is circular, but in the vicinity of the intima, there is a certain number with a different orientation (oblique or longitudinal).

Regarding the tunicae, the ascending aorta and aortic arch present a comparable proportion with the pulmonary trunk and a circular disposition of the majority of the muscle cells in the media (fig. 1). The elastic component is represented by elastic lamellae with a comparable thickness. The thickness diversity is lower than in the pulmonary trunk. The distance between the lamellae is comparable throughout the media thickness and their orientation is circular (fig. 2).

The thoracic descending aorta presents a slightly thicker adventitia in comparison with the aortic arch and ascending aorta. Nevertheless, it maintains the general aspect of an elastic artery.
The elastic lamellae present a close thickness and disposition to the ones in the aortic arch.

The abdominal descending aorta has a thicker adventitia than the thoracic segment, and the elastic lamellae become more polymorph and have a greater distance between them.

In the subclavian arteries (left and right), media is still the most developed tunica, but the adventitia is thicker than in the anteriourly presented arteries, representing $30-35 \%$ of the wall thickness. Muscle cells are circular and with a relatively regular disposition, organizing into rows, disposed at a certain distance from one another. The elastic lamellae have a circular orientation, a comparable thickness with the ones in the aorta, but they are obviously less and the distance between them is larger.

In carotid arteries (left and right), adventitia slightly increases in size and the muscle cells are clearly disposed in several circular rows (fig. 3). The elastic lamellae have a circular disposition and a larger distance between them than the ones in the arteries previously described (fig. 4).

Starting with the iliac arteries, tunica adventitia evidently thickens, becoming approximately $40 \%$ in internal iliac arteries and up to $50 \%$ in external iliac arteries (fig. 5). The internal side of the wall is sinuous, which makes the general aspect of the iliac arteries in rabbit comparable with that of the muscular arteries. The elastic tissue stain confirms the fact that the iliac arteries in rabbit have a typical muscular artery structure, with elastic limitants (internal and external). As for the rest of the tunica media, it does not contain elastic lamellae (fig. 6).

Large arteries' caliber in rabbit depends on the position of each artery in the circulatory system, and it gradually decreases as the arteries get further away from the heart. The proportion between the three tunicae in the first segments is in favour of tunica media, which occupies up to $80 \%$ of the wall thickness. It gradually modifies, so that in the last arterial branchees taken into study it represents a little over $50 \%$. Thus, tunica media occupies approximately $80 \%$ of the arterial wall thickness in pulmonary trunk, ascending aorta and thoracic descending aorta, 70\% in abdominal descending aorta and subclavian arteries, $60 \%$ in carotid arteries and $55 \%$ in iliac arteries. The thickness of tunica adventitia gradually increases from approximately $15 \%$ (aorta) to $45 \%$ (external iliac arteries). 


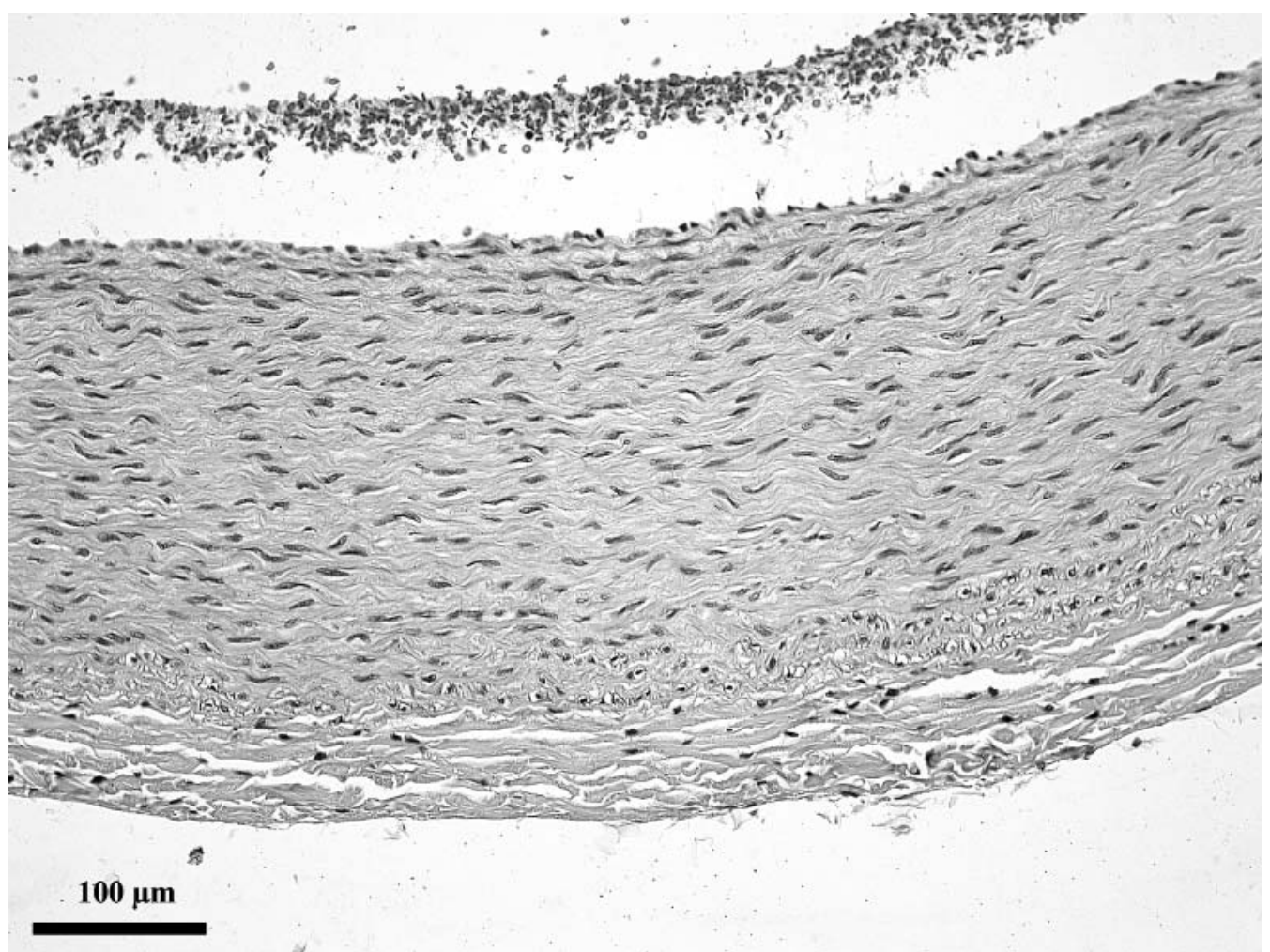

Fig. 1. Aortic arch (Goldner's Trichrome stain)

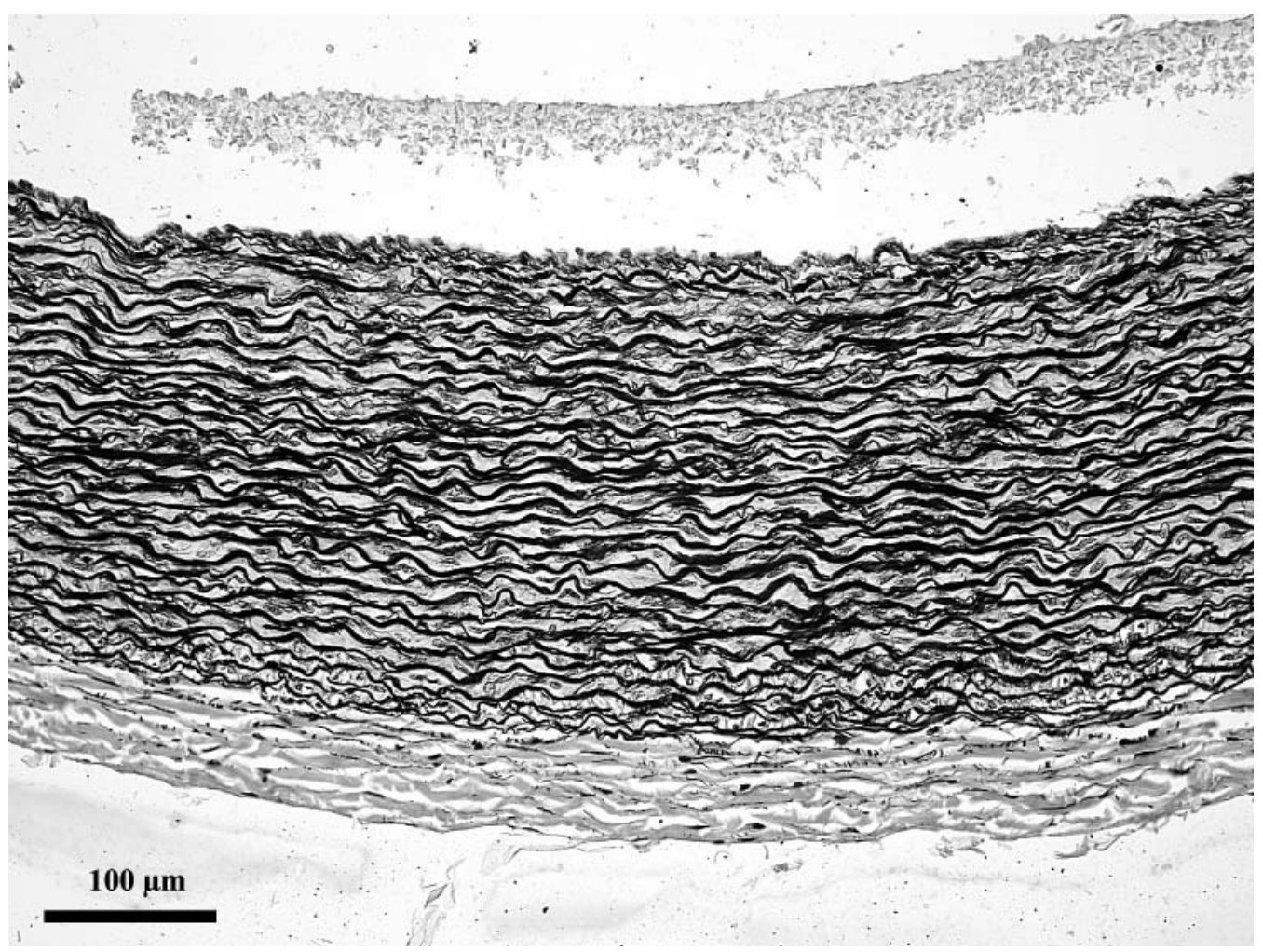

Fig. 2. Aortic arch (Verhoeff's stain) 


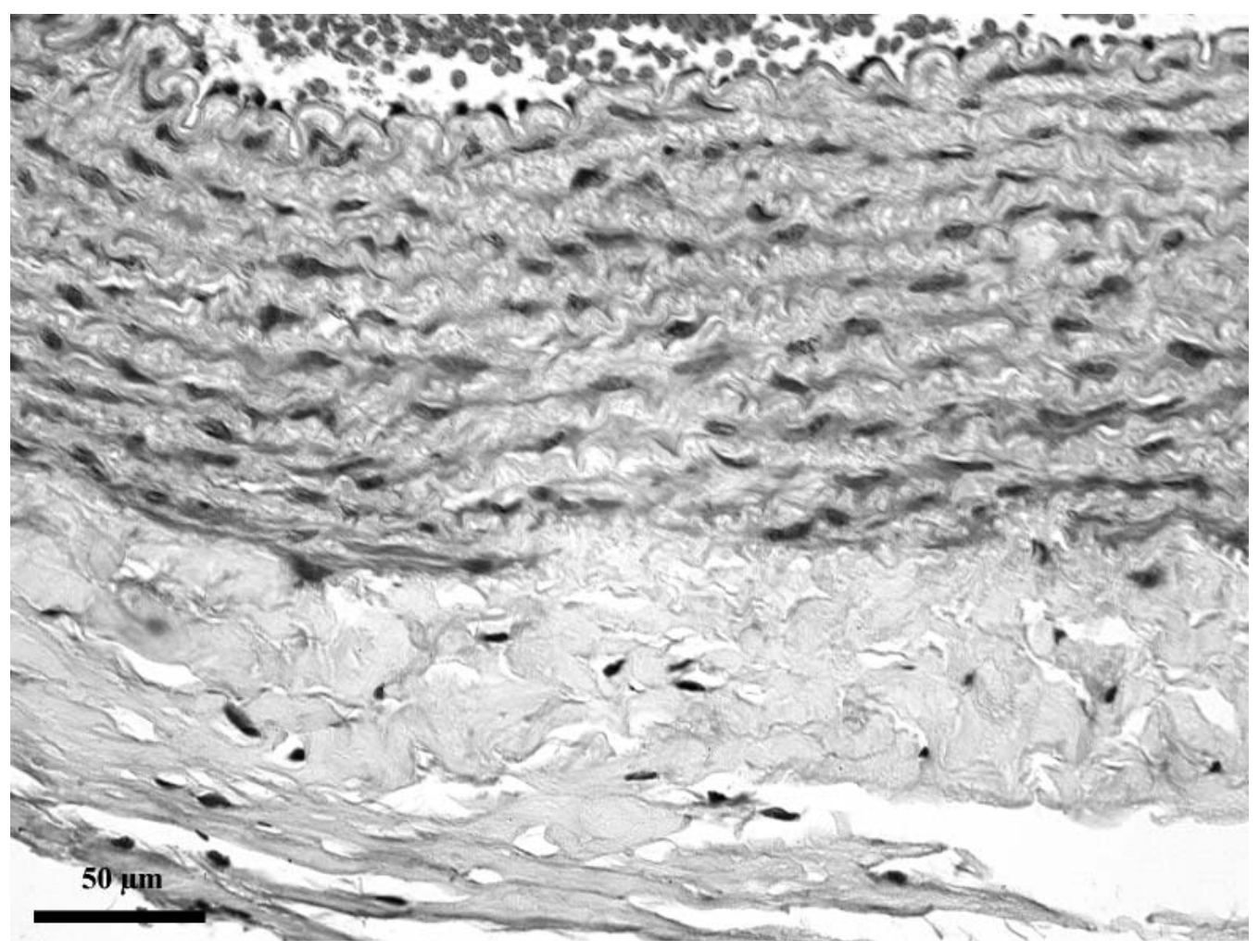

Fig. 3. Right carotid artery (Goldner's Tricrome stain)

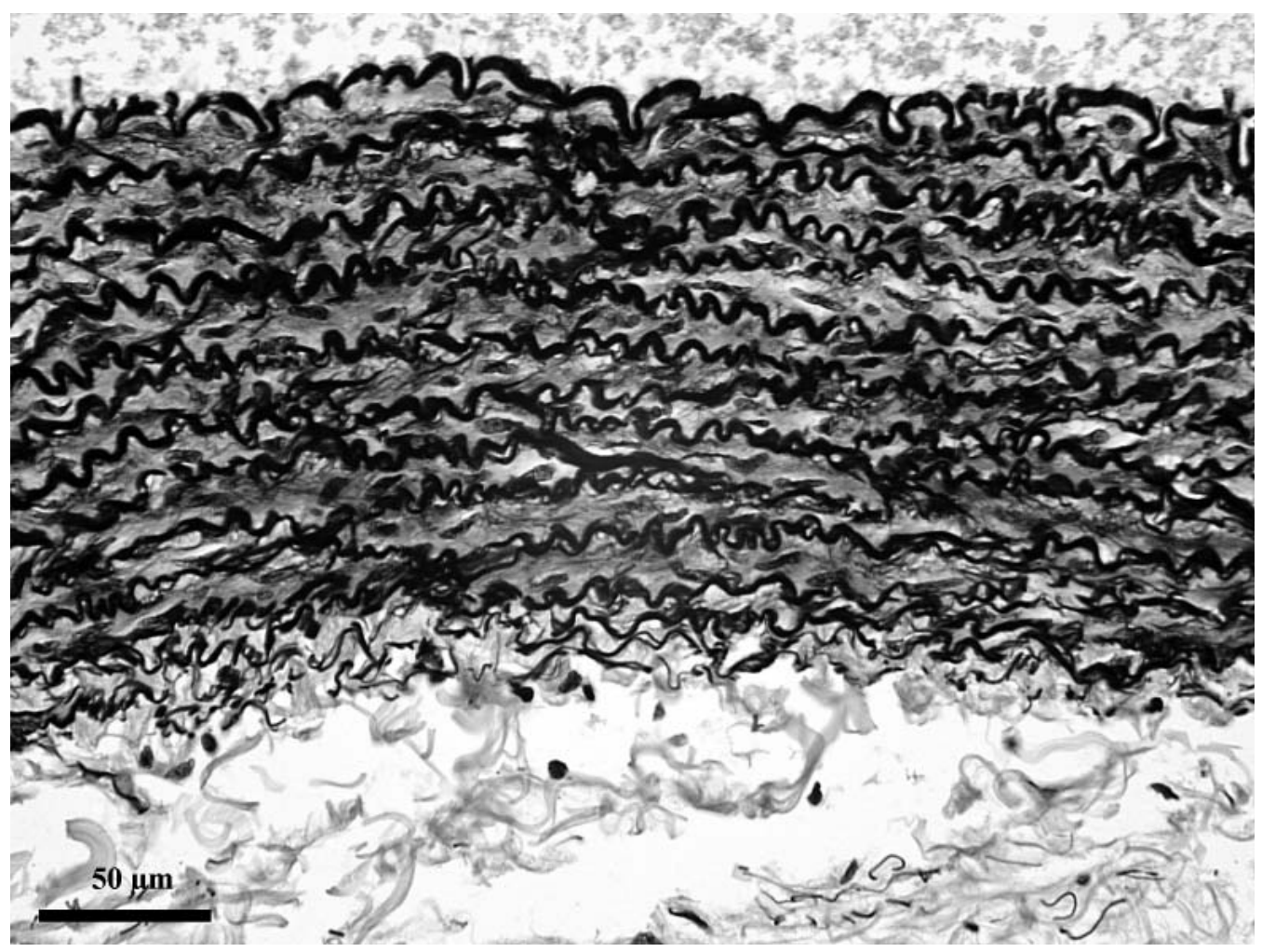

Fig. 4. Right carotid artery (Verhoeff's stain) 


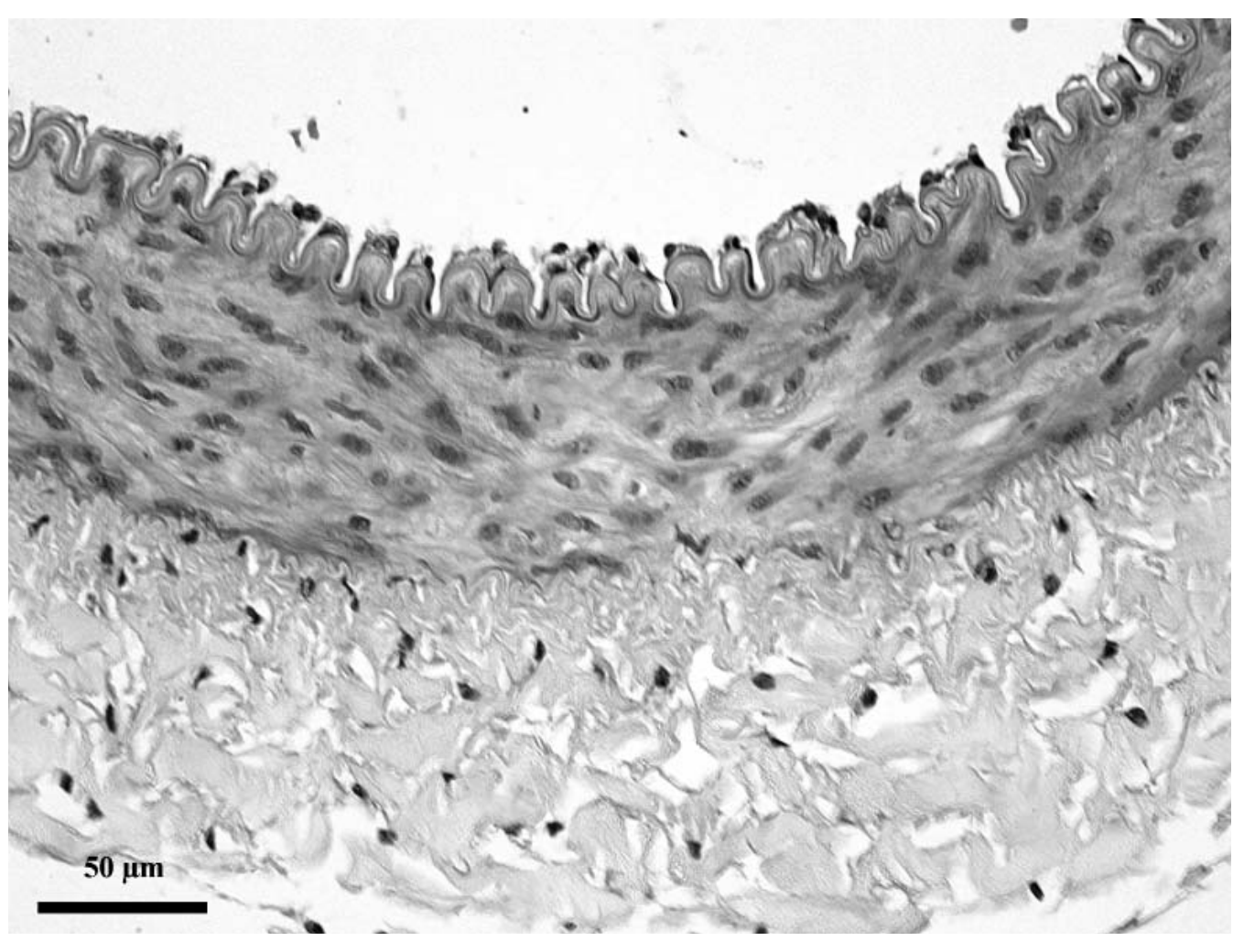

Fig. 5. Right external iliac artery (Goldner's Tricrome stain)

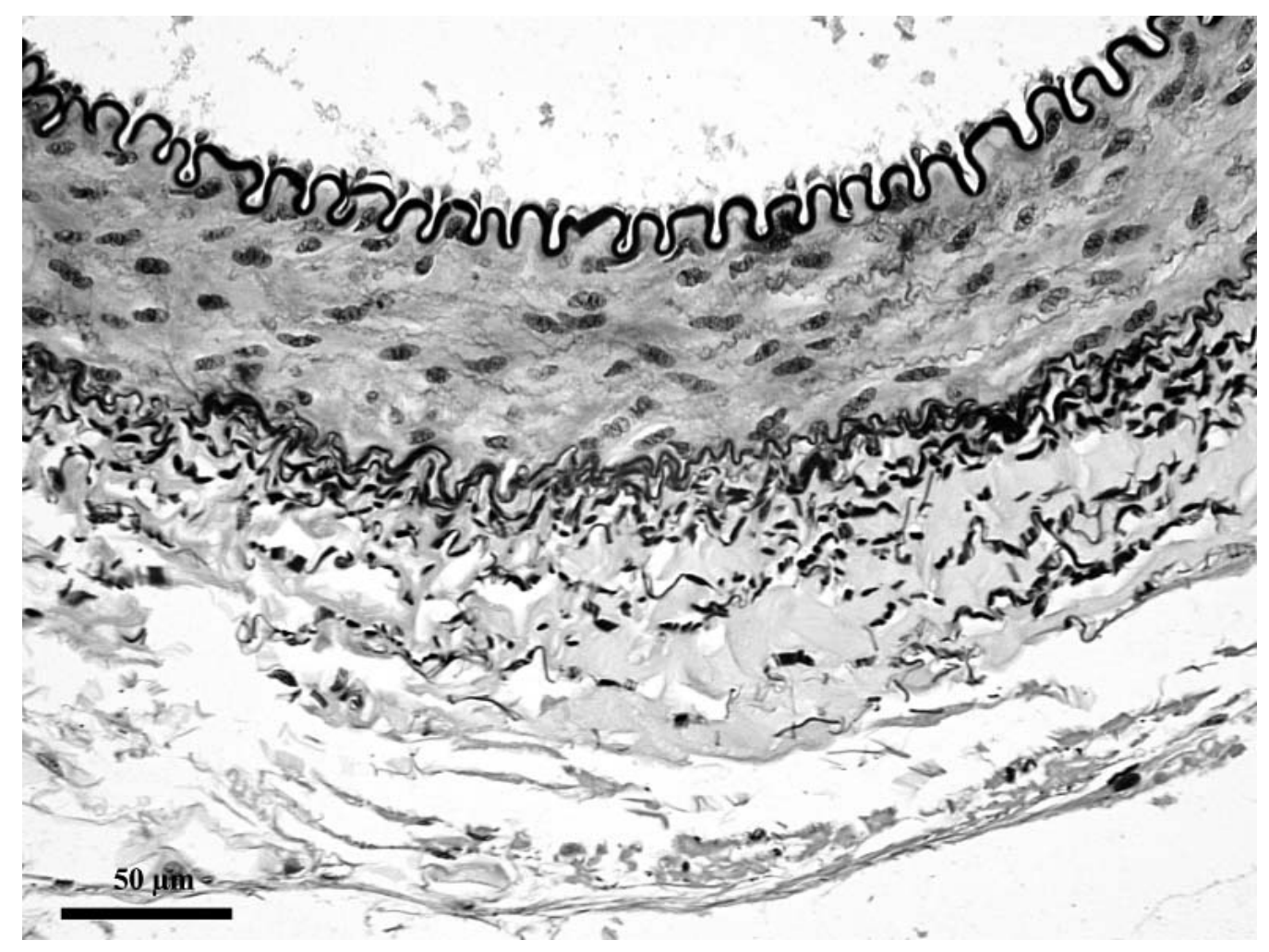

Fig. 6. Right external iliac artery (Verhoeff's stain) 
Structural assessment of tunica media of the arteries taken intor study also highlights other differences beside the ones linked to the thichness of tunicae. In the case of the arteris in which tunica media occupies approximately $80 \%$ of the arterial wall thickness (pulmonary trunk, ascending aorta, aortic arch and thoracic descending aorta), the majoritary component of the media is the elastic one. This is the reason why, these arteries can be graded as typical elastic arteries. Certain differences exist between the arteries that fall under this cathegory, regarding the thickness of the elastic lamellae and to a certain extent even their disposition. The great majority of these arteries present thick and relatively uniform elastic lamellae, regularly disposed so that the distance between them is comparable. The pulmonary trunk is an exception, in which the elastic lamellae are rather polymorph regarding their thickness and disposition. In the case of arteries in which the media occupies approximately 70\% (abdominal descending aorta and subclavian arteries), the thickness of the elastic lamellae is comparable with the one in the arteries previously described, but their density is obviusly lower. The ellastic lamellae are disposed at a certain distance and the areas between them are mainly occupied by smooth muscle cell, disposed circularly. The proportion between the elastic and muscle component in tunica media of thses arteries seems somehow comparable (50-50\%), so that these arteries can not be considered to be typical elastic arteries. On account of the fact that the elastic lamellae are relatively thick and have a circular disposition, even if the elastic component does not exceed $50 \%$ of the tunica media structure, we consider that these arteries can be classified as elastic-muscular arteries. Arteries in which media occupies approximately $60 \%$ of the arterial wall thickness (carotid arteries) present elastic lamellae with a circular disposition, but the distance between them is larger than the one in the elastic-muscular ateries previously described. The space between the elastic lamellae is occupied by smooth muscle cells, which are majoritary in tunica media of this arteries. In this context we consider the rabbit carotid arteries as being musculo-elastic arteries. The two categories of arteries make the transition from elastic to muscular arteries, which is the reason we consider that all arteries in this category are transitional arteries.
Arteries in which tunica media occupies approximately $55 \%$ of the wall thickness (internal and external iliac arteries) present a media comparable with the muscular arteries, formed out of smooth muscle cells circularly disposed on layers. Between tunica media and initma there is a thick and sinuous elastic limitant, comparable to the one in the muscle arteries, and between tunica media and adventitia, the external elastic limitant is present, which is formed out of a few thinner elastic lamellae. After the described aspects, internal and external iliac arteries in rabbit, fall under the muscular arteries category.

Based on the results we obtained, we can claim that large arteries in rabit present structural differences, which are more pronounced as the artery to which we refer, gets further away from the heart. By comparing the our data to the ones in the specialty literature, we observe that there are differences between species. Thus, Awal et al. (2001) stated that in guines pigs, the abdominal descending aorta is a typical elastic artery, whereas we observed that in rabbits it is a transitional artery. Furthermore, these authors sustain that in guinea pigs, iliac arteries are transitional arteries, while we determined that in rabbit they are typical muscular arteries.

\section{CONCLUSIONS}

Large arteries in rabbit present a different proportion between tunicae. In the first segments, tunica media predominates, but as the arteries get further away from the heart, it gradually decreases, and tunica adventitia increases, so that it occupies almost half of the wall thickness in iliac arteries.

The proportion between the elastic and muscular component in tunica media of the studied arteries shows that the first segments are typical elastic arteries, the next ones are transitional arteries and the last ones are muscular arteries.

Acknowledgements. This paper was published under the frame of European Social Fund, Human Resources Development Operational Programme 2007-2013, projectno. POSDRU/159/1.5/S/136893

\section{REFERENCES}

1. Adlersberg L, Brătianu S, Crișan C, Gundisch M, HagiParaschiv A, Niculescu IT, Rîmniceanu C, Țupa A (1955). Histologie, vol II, Ed. Medicală, București. 
2. Awal MA, Prodhan MAA, Kurohmaru M, Matsumoto M, Hishinakagawa H (2001). Microscopic studies on the arterial walls of mainarteries supplying the mammary glands of guinea pig (Cavia porcellus) atdifferent reproductive stages. Vet. Arhiv. 71: 19-30.

3. Damian A (2001) Anatomie comparată, Splanchnologie, Ed. Academic Press, Cluj-Napoca

4. Junqueira LC, Carneiro J, Kelly RO (1998). Basic Histology, 7-th Edition, Appleton \& Lange Norwalk, Connecticut.

5. Leeson RC, Leeson TS, Paparo AA (1985). Textbook of histology. W.B. Saunders Company, Philadelphia.
6. Mureşan E, Bogdan AT, Gaboreanu M, Baba AI (1974). Tehnici de histochimie normală şi patologică, Ed. Ceres, București.

7. Oana L, Timen A, Beteg F (2006). Anesteziologie și propedeutică chirurgicală veterinară, Ed. Risoprint, ClujNapoca.

8. Raica M, Mederle O, Căruntu ID, Pîntea A, Chindris A-M (2004). Histologie teoretică și practică, Ed. Brumar Timișoara.

9. Ross HM, Reith JE (1985). Histology a text and atlas, Harper International Company. 